\title{
Some Issues in the Measurement of Profit Accountants
}

\section{versus Economists}

\author{
Zubair Hasan (Corresponding author) \\ Professor Emeritus; Economics \& Finance \\ INCEIF: The Global University of Islamic Finance \\ Kuala Lumpur, Malaysia \\ Tel: 91-9718-781-675Ｅ-mail: zubhasan@ gmail.com
}

Received: April 18, 2017 Accepted: September 26, 2017 Published: September 30, 2017

doi:10.5296/wjbm.v3i2.11945ＵRL: http://dx.doi.org/10.5296/wjbm.v3i2.11945

\begin{abstract}
This paper discusses a topic rarely addressed in the literature on profit theory over the decades. In empirical work on subjects like growth, efficiency and welfare in mainstream or Islamic economics business profits at times appear as one of the determinants. Such studies perforce use profit data reported in the accounting records. This data is invariably at variance in important ways with the economists' theoretical view of profit. The cause of divergence is the cosmopolitan forward looking ex ante view of entrepreneurism the economists take in the matter as opposed to the narrow conservative ex post focus of the accountants needed to protect the interest of business proprietors who pay them for the job. There is a need to narrow this gap to improve the results of empirical explorations. This paper identifies and examines some issues like maintenance of capital, evaluation of inventories and the impact of conservatism as causes of divergence as focal points for reducing the gap. It concludes that the economists are obliged more to take cognizance of accounting compulsions than the other way round in the reconciliation process.
\end{abstract}

Keywords: Business profits, Efficiency, Capital maintenance, Inventory evaluation, Conservatism 


\section{Introduction}

The atomic analysis of profit at the theoretical level has caused great divergence of opinion on the subject among the economists and has, in addition, widened the wedge between their views on profit on the one hand and of the accountants on the other. The accountants see the firm, not the waning entrepreneur like the economists, as the seat of profit. They take a wider 'catch-all' view of profit including in the packet implicit returns, windfalls, scarcity rents, and monopoly revenues which imparts realism to the concept. If the economists relax on their hair splitting analytics, the two approaches may promise a workable reconciliation. Minimization of the gap must be attempted as the accountants provide the techniques for the measurement of profit. The economists need the data thus generated for the testing of their hypotheses as also for business policy evaluations. Thus, they need to relook their theoretical structures. However, this does not mean that accountants have no responsibility, or cannot do anything, for reducing the conceptual gaps on profit between the two disciplines. There are reasons, we shall presently see, that put greater responsibility on the economists for initiating effort at reconciliation.

Even if the economists shift the locus of profit from the heuristic entrepreneur to the firm, and broaden reasonably their definition of profit, they would remain at odds with accounting practice on the measurement issue (Hasan, 2016). Some of the main questions giving rise to disagreement are: Should we have an ex-post view of profit or ex-ante? What is the meaning of capital? Why, and in what sense - nominal or real - must capital be kept intact? How far can modern accounting be expected to eschew conservatism and become forward looking? Palpably, the answers to such sort of questions, crucial to the measurement of a profit, would depend mainly on the time dimension of a study. For, it would be quite simple to measure profit for the entire life of a business firm. From the sum of amounts received will be deducted the amounts paid into or invested in a business during the firm's entire life; the difference thus obtained would be the owners' profit or loss. The results of such a calculation are not, however, of much significance except for purely financial concerns or business undertakings with extremely short lives. ${ }^{2}$ And though this method has the advantage of finality and precision - indeed it is the only method of profit computation that can conceivably be free of error, but its insistence that profit determination must await the final liquidation of a business sharply limits its usefulness.

Businesses are not founded for liquidation but with the hope that they would prosper and continue for long. The span of life of a business firm has been greatly lengthened with the advent of the modern corporation. The case of practical importance, as well as of theoretical interest, therefore, is that of measuring periodic profits of a going concern. The notion of periodicity here is arbitrary; for, there is no logical basis to decide the relevant time dimension. Accounting has fixed the periods for profit measurement not as a matter of rule but according to the conventions of the line of industry in which the firm operates or the nature of its business. The element of arbitrariness in choosing the time-dimension for the measurement does not, however, detract from its practical significance. The periodic measurement of the profits of a business firm is of vital importance from the points of view of its owners, management, workers and creditors. The consumers and the government, the 
economists, and the politicians are all interested in the periodic measurement of business profits for reasons of their own.

The accountants had to feel greater impact than the economists of the periodicity imperative. The latter never cared to forge their own tools for measuring profit and continue to rely on accounting records as the primary source of statistics for their use. Accounting is not yet a perfect art and the compulsions of his role in measuring profit do not leave much scope for the accountant to modify his methods to suit the needs of the economist. Thus viewed, much of the criticism of the accountant and his methods by the economists, though understandable, is uncalled for. So long as accounting records remain the primary source of data for the measurement of profit, the economists have to go more than half way to meet the accountant. It is only with this understanding that we can proceed in a useful way to reconcile the views of the economist and the accountant on the basic issues thrown up by periodic measurement of profit.

Periodic measurement of profit requires one to distinguish between ex-post and ex ante concepts of profit. Conventional accounting is largely concerned with past events. Historical costs and historical revenues lie at the very foundation of accounting techniques. Profit that accountants measure is essentially, ex-post in nature and content. This accounting view of profit has been widely criticized by the economists. An evaluation of this criticism would lead one to conclude that the basic definition of profit should be ex-post, even if ex-ante profit is considered as a more proximate determinant of economic behavior.

For discussion, this paper is divided into five broad sections including the introduction. In Section 2 we examine the concept of capital and the versions of maintaining it intact in a going concern from the accounting and economic viewpoints. Section 3 carries this discussion forward to analyze the pros and cons of the accounting approach to maintain capital essentially in money form and the economist approach to maintaining it in some real sense. Section 4 discusses the role of inventory valuation in the measurement of profit including the contribution to cyclical fluctuations of the two major practices of issuing materials to works, the lifo and fifo systems. In Section 5 is taken up the difference that the accounting conservatism in measuring profit makes as compared with the forward looking entrepreneurial approach of economics. Finally, Section 6 contains a few concluding observations. The usual literature review section is missing in this paper because the issue of profit measurement as conceived here has rarely been taken up in accounting or economics.

\section{Concept of Capital}

Issues in the measurement of profit mainly stem from the going concern notion of a business enterprise. Periodicity lends meaning and significance to the organism of a firm. Both economic theory and accounting practice conceive of this organism in terms of the capital invested in the firm. Their approaches to the reckoning of capital invested, however, differ in an important way.

The definitional characteristic of capital for the economist is that it is something real in character. "It consists of all those goods existing at a particular time which can be used in any 
way so as to satisfy wants during subsequent periods (Hicks, 1960, 75)". The organism of the firm is nothing but an aggregation of assets devoted to the production of goods or service over a period of time. In other words, lands, buildings, plant and machinery, furniture and fixtures, stocks of raw materials, and of finished and semi-finished goods will broadly constitute the economic capital of a going concern (Bray, 1952, 15). On the other hand, the accounting concept of a firm's capital has two versions (A) broad and descriptive, and (B) narrow and analytical.

\subsection{Accounting Versions}

(A) The broad view

The broad and descriptive version is based on the classification of business outgoings during a period into current and capital transactions. The distinction is essentially generic in character, and problems arise when attempt is made to set the line of demarcation. To meet the situation accountants have directly associated capital expenditure with slow moving outgoings made for the purpose of acquiring relatively durable assets which are held with the object of earning revenue and not for the purpose of sale in the ordinary course of business. Expenditures on the acquisition of lands, buildings, plant and machinery, furniture and fixtures etc. easily fall into this category. Constitutional outgoings such as the preliminary and formation expenses incidental to join stock companies, and some deferred charges are taken into the same generic classification. However, it is not always easy to decide if an outgoing associated with an existing asset is necessarily a capital expenditure.

One of the accounting tests for this purpose is based upon the influence such expenditure would have on the life and efficiency of the asset concerned. If it increases the life of the asset or promotes its productivity, the outgoing would be classified as capital expenditure. On the other hand, if it has only maintained the asset in the working order, it is regarded as current expense, like that on fuel, light, wages, carriage, raw materials consumed etc. The former have relative stability in the balance sheet statement of assets, liabilities and proprietorship worth, while the latter find their place in the income, or profit and loss account. Accounting developed primarily as a tool of private business and accountants thus have a limited perspective. The center of their attention has mostly been the interests of the owners of business. Therefore, they essentially adopt a narrow view of capital wherein it is only regarded as proprietorship worth. They look upon the amount of money or money's worth coming in to start a business as its original capital and seek to adjust it in the light of later contributions and withdrawals, capital gains or losses, and retained profits. Although accountants maintain a clear distinction between proprietorship worth and the general pool of assets to which it lays claim, they also insist on a close tie between the two. This is perhaps the main cause of the intimate association of accounting techniques with historical costs (Note 1).

(B) The narrow version

The broader and descriptive view of capital in accounting usage has been largely responsible for the evolution of the design of accounts while the narrow analytical view has been an 
essential tool in measuring the profitability of the undertaking to its owners. In any case, accounting concept has tended to remain on the money end of things as opposed to the economists' real or physical view of capital. This distinction between economic theory and accounting tradition would have been only of academic value in a stationary state if only the value of money continued to remain fairly stable. This, however, assumes great importance, especially with reference to the problem of maintaining capital intact under dynamic conditions and rapidly changing price levels.

\section{Maintenance of Capital}

Although accountants, as well as economists, emphasize the need of maintaining capital intact to preserve the organism of a going concern, their approaches to the problem substantially differ. Consistent with his narrower view of capital, the accountant is concerned primarily with the maintenance of proprietorship worth of a business firm, expressed in money terms. When confronted with periodic measurement of profit his object is that the whole cost of output produced and sold, during the period must be recovered. A good part of the expenditure is directly allocable to the operations of the current period but there may be a considerable amount of money spent which cannot be so allocated and has to be spread over a series of short periods. Moneys spent on fixed assets and some deferred expenditures fall into this latter category. We shall, however, confine ourselves for the moment, to expenditure on fixed assets as this leads to the problem of capital maintenance, which accounting attempts to solve by providing for the depreciation of these assets.

\subsection{Depreciation in Money Terms}

The conventional accounting approach regards depreciation as

"that part of a fixed asset to its owner which is not recoverable when the asset is finally put out of use by him. Provision against this loss of capital is an integral part of cost for conducting business during the effective commercial life of the asset and is not dependent on the profit earned", (Bray, 1952, 66).

The amount of periodic depreciation (Dn) depends upon the acquisition cost of the asset (Ac), its probable scrap value $(\mathrm{Sv})$ and the number of time units during which the asset is expected to be commercially useful to the undertaking (Nt). Symbolically:

$$
\mathrm{D}_{\mathrm{n}}=\frac{(\mathrm{Ac}-\mathrm{Sv})}{\mathrm{Nt}}
$$

Of the elements in the calculation of depreciation specified in the equation, Ac is known, $\mathrm{Sv}$ can generally be estimated only within somewhat wide limits and $\mathrm{Nt}$ is highly susceptible to precise calculation. Thus, provisions for depreciations are mostly a matter of estimation based upon the available experience, knowledge and assumptions rather than of precise determination. It is important to observe that to the extent the accountants have to estimate the depreciation chargeable to the revenues of a particular period segment, an ex-ante element creep into the calculation, as in economics, even in the accounting concept of profit. 


\subsection{Depreciation in Real Terms}

In contrast to accounting view of depreciation based on the money values of assets, the economists have always insisted that the capital of a going concern should be maintained intact in some physical sense. For them the preservation of a firm has been more important than the money value of fixed assets. The firm, as a going concern, must end up the period with the same potential capacities, as it began with, before it can assess its disposable profit (Note 2). Thus for a continuing enterprise, the function for depreciation accounting should be to provide resources adequate enough for the maintenance of real assets. This requires the abandonment of original money costs of assets in favor of their replacement costs as a basis for calculating the amount of depreciation. Thus, in each case the sums of money allocated to depreciation from the current revenues of different period segments should ultimately accumulate to an amount which would be sufficient to enable the replacement of the asset in question when it becomes worn out or obsolete, by a reasonably equivalent asset that would keep intact the productivity of the plant.

There is not much to choose between the original value base of the asset or its replacement cost for depreciation, if the price of the asset remains unchanged over time. In fact, the original or historical cost concept of depreciation in accounting has been, by and large, a legacy from periods of relatively stable prices. The war and interwar years of wide fluctuations in prices, however, brought out clearly the weakness of this concept and the economists put the accountant and his methods to close scrutiny and scathing criticism (Note 3). Depreciation calculated on the basis of original cost of assets falls too short of replacement requirement during periods of rising prices. The erosion of real capital became so obvious and alarming during war and post-war inflations that accountants themselves began to doubt if their traditional approach could any longer be defended (Note 4). A closer examination of the issues involved in the cyclical fluctuations contextual to the economic view of maintaining capital in real terms would, however, reveal that the day has not altogether been lost for the accountants.

The contention of the economists is that the purpose of depreciation in the case of a continuing enterprise can hardly be anything except to provide for the replacement of assets after the expiry of their useful life to the firm. One way of achieving this object is to view both income and capital in some physical sense. Capital would be maintained intact so long as the initial capital stock remains absolutely unchanged in physical terms. The depreciation here would form that part of the income flow from the selling of goods and services which replaces the physical deficiency of the initial stock of capital goods (Note 5). Some inherent ambiguities of this approach apart, it makes, save under very different circumstances, the comparison of the resultant profit of different firms extremely difficult because of the incommensurability of the physical unit of the measurement involved (Pigou, 1951, p. 295). This difficulty is sought to be obviated by using the money prices at some point of time as weights. This brings us to the second, and more widely used, concept of "real capital maintenance in money terms" (Note 6). Let us call it as the RCM concept. 


\subsubsection{The RCM Concept}

To reiterate, according to the RCM concept depreciation has to be measured on the basis of replacement costs instead of original values. If we assume that the physical quantity $\left(\mathrm{q}_{0}\right)$ of a particular asset would become $\left(\mathrm{q}_{\mathrm{i}}\right)$ (Note 7) after its effective life measured by time interval $\mathrm{t}_{0} \ldots \ldots \mathrm{t}_{\mathrm{n}}$, the physical erosion of capital would be expressed by $\mathrm{q}_{0}-\mathrm{q}_{\mathrm{i}}$ or $\Delta \mathrm{q}$. The accountant values this depreciation at original price $\left(\mathrm{p}_{0} \mathrm{q}\right)$. If prices do change over time the economists insist that depreciation should take into account not only the physical depreciation of an asset but also the effect of change in its price. This may be called as the price component of depreciation. If $\mathrm{p}_{0}$ becomes $\mathrm{p}_{\mathrm{i}}$ at time $\mathrm{t}_{\mathrm{n}}$ this price component would be $\Delta \mathrm{p} \Delta \mathrm{q}$. It will be positive if $\mathrm{p}_{\mathrm{i}}>\mathrm{p}_{0}$ and negative if $\mathrm{p}_{\mathrm{i}}<\mathrm{p}_{0}$ for a given $\Delta \mathrm{q}$. The total depreciation (D) in money terms that would maintain capital in real sense may now be found out by combining the physical $\left(\mathrm{p}_{0} \Delta \mathrm{q}\right)$ and the price $(\Delta \mathrm{p} \Delta \mathrm{q})$ components in the following way:

$$
\mathrm{D}=\left(\mathrm{p}_{0} \Delta \mathrm{q}\right) \pm(\Delta \mathrm{p} \Delta \mathrm{q})-\mathrm{Sv}
$$

If the time span (to.....ti) of the effective life of the asset is composed of $\mathrm{Nt}$ segments for the measurement of profit, the periodic depreciation (Dn) will be given by the following formula minus the scrap value of the asset:

$$
\mathrm{D}_{\mathrm{n}}=\left[\left(\mathrm{p}_{0} \Delta \mathrm{q}\right) \pm(\Delta \mathrm{p} \Delta \mathrm{q})-\mathrm{Sv}\right] / \mathrm{Nt}
$$

The basic requirements for finding depreciation using the above formulae are to know, or estimate, the time when the asset in question would be replaced $\left(t_{n}\right)$, the price of an identical asset at that time $\left(\mathrm{p}_{\mathrm{i}}\right)$ and the scrap value of the old asset at that time. All these estimates are, by and large, a matter of subjective considerations of entrepreneurs and make the resultant profit concept inherently imprecise and extremely difficult, if not impossible, to measure and interpret. Consider for example the problem of comparing the profits of a number of business firms, using identical assets, if their managements expect to replace that equipment in future at different times, when price levels would be different. This difficulty, it is suggested, may be obviated if current costs are used in place of replacement cost. Such a policy would require upward or downward adjustment of original cost with every change in the prices of identical assets. This adjustment has to be made regardless of the date of replacement and even if no replacement takes place at all. Ex-post profit is now independent of the entrepreneurial expectations and hence clearer to that extent. A number of practical difficulties, however, will have to be faced.

\subsubsection{The Difficulties}

1) If the price of the asset in question changes, erratically or the change is short lived, it may play havoc with the measurement of profit. The suggestión of Bray $(1952,68)$ to circumvent this difficulty by having regard for the general trend of replacement costs rather than the cost known at the accounting date, is not of much help. For, one must now face difficulties, both conceptual and computational, regarding the general trend of replacement costs.

2) A business will hardly replace its worn out equipment with something which is exactly 
the same. In this age of fast technological changes and scientific inventions the firm will take up new, sometimes cheaper, forms of equipment to fulfill similar functions more efficiently. Under these circumstances there is hardly any relevance of the current cost of the old asset for purposes of replacement.

3) "If replacement funds are set aside currently on the basis of the current market prices of the assets to be replaced, they may be excessive if prices fall or deficient if they rise. Suppose, while a particular asset is still held by a business enterprise, the price of an identical asset goes up and continues to remain at that high level. The total depreciation allowance in this case - being the sum of a number of early deductions based on original cost and later provisions based on current price, will be less than the actual replacement cost of the asset in question. Just the opposite will happen if prices were high at the time of acquisition but fell to a constantly low level afterwards. This shows that past provisions accumulating in the depreciation reserve should be updated by some adjustment. However, the price assessment of such an adjustment would be, by and large, a matter of judgment even though the guiding considerations may be clear. One method of avoiding this difficulty often advocated by modern accounting is to invest the depreciation fund out of business in some real assets. This would be helpful only if the price of the investment and the asset concerned move in the same direction, and by identical magnitude. This will rarely happen and the greater is the discrepancy in this movement on either count the lesser would be the advantage of not keeping the depreciation fund in business itself.

4) At times, the current prices of assets identical to those which are to be replaced are not available and have to be estimated through the use of price index numbers of the main group of capital goods. Apart from the limitations of index numbers which are well known, their use in this connection makes the RCM concept subsidiary and derivative (Note 8).

5) The basic aim of RCM concept is to maintain the same service stream as was provided by old assets when these were new (Note 9). This suggests that the firm should be able, in a broader sense, to replace not only its material and fixed assets but the non-material and current assets as well. It is obvious that the RCM concept would encounter a number of additional difficulties if extended to cover these assets also.

It thus comes about that the accounting approach to the problem of capital maintenance, based on the original money values of the assets, is more precise and clearer than the economic view of maintaining capital in some real sense. It has great computational utility and is at once consistent with our view that the basic definition of profit must be ex-post.

This conclusion, however, need not make the insistence of the economist on maintaining capital in some real sense insignificant. It is difficult to understand as to how a going concern can continue to earn profit in the long run if it does not maintain its capital in real terms. For, a management oblivious to this need may be distributing the capital of the firm by way of dividends over periods of continuously rising prices. This may ultimately put the very existence of the firm in jeopardy. 


\section{MInstitute ${ }^{\text {Macrothink }}$}

World Journal of Business and Management

ISSN 2377-4622

2017, Vol. 3, No. 2

The arguments advanced above are, therefore, meant only to emphasize that the RCM concept need not blur the basic definition of profit. However, when the replacement cost of a fixed asset far exceeds its original cost by reason of a continuous rise in prices, this must engage our attention but must be treated as a separate and distinct problem from that of depreciation. Replacement considerations must be looked into more as questions of policy relating to the utilization of profit earned rather than as a matter pertinent to its measurement. Different sections of society are exposed to the effect of changes in the value of money in accordance with the respective price elasticity of their incomes. Tax legislation does not seek to counter the effect of price changes on different sections of society. This may be regarded as a defect of the present legislation but so long as we are governed by the law as it is, to allow the charging of depreciation at replacement cost of assets in business accounts in favor of the recipients of profits would clearly constitute an unjust discrimination.

The business practice of building up strong general reserves out of current profits is an effort to guard against future contingencies. It is difficult to understand why possible rise in the replacement cost of assets should not be treated as one of these contingencies. Or alternatively, why can we not build up a reserve called, say, the Fixed Block Real Value Maintenance Reserve like the Investment Fluctuation or Exchange Variation reserves? The creation of such a reserve out of periodic profits, facilitating adjustment of asset values when their prices change, would help accountants meet the objections of the economists, and conform to the legal view of depreciation.

\section{Inventory Valuation}

A going concern not only requires plant, equipment raw materials and manpower in order to turn out goods and services, it must also carry a considerable quantity of commodities during a period of profit measurement, and often from one such period to another. Manufacturers keep sufficient quantity of raw materials on hand in order to avoid interruptions to production. There must almost always be some goods-in-process as the cycle of manufacturing operations invariably takes time to complete. Again, many manufacturers carry the stocks of finished products with a view to avoiding delays in filling the customers' orders. Likewise, the main function of most wholesalers and retailers is to have an extensive stock of all sorts of goods ready at hand so as to provide purchasers with a wide range of choice. And finally, many firms may sometimes carry inventories in excess of their normal requirements with a purely speculative motive.

Whatever be the need for and motive for carrying inventories, their existence is of great significance in the affairs of a going concern. On the one hand, they constitute an important element of the cost of goods sold, on the other, they form an integral part of the asset organism continuing enterprise; accounting techniques used for their valuation in each case are well known.

\subsection{The First in First Out (Fifo) System}

The inventory of finished products becomes expense when sold. This expense, according to accountants, should be measured by the acquisition cost of these products for finding out the 
profits of the period under review. As different lots of inventories are hardly purchased at identical prices, the estimation of their acquisition cost, becomes the crux of the problem. The conventional accounting uses the first-in-first-out (Fifo) basis for arriving at this estimation on the assumption that physically materials move out of inventory on, more or less, a first-in-first-out basis. This is quite realistic; the oldest stocks are normally used up first. The selling price decisions of business are, however, influenced more by current costs of inventories rather than by their historical values (Anthony, 1970, p. 231) The conventional Fifo system, therefore, results in the emergence of what economists call as 'inventory profits' during periods of rising prices and 'inventory losses' when prices are falling. In each case the goods are sold at prices commensurate with current costs while the profit and loss account is charged with earlier (lower in inflation and higher in deflation) cost of these goods.

Thus viewed, part of the profit realized in sales is an "inventory gain" when prices are rising and vice versa (Crum 1932, p. 231). The magnitude of this inventory gain (or loss) will depend upon the staying time of materials in inventory, the volume of conversation costs, if any, the degree of correlation between selling prices and current costs, and above all, the speed of the rise or the fall in prices. These realized inventory profits (and losses) apart, the Fifo system breeds purely paper profits (or losses) which may or may not be realized in subsequent periods. The source of these unrealized inventory differentials in the estimation of the excess in the value of inventory at the end of the period over that at the beginning of the period. For, if the excess is positive it acts as a partial offset against other items in the cost of goods sold, thus raising the reported profits; if the excess.

These realized inventory profits (and losses) apart, the Fifo system breeds purely paper profits (or losses) which may or may not be realized in subsequent periods. The source of these unrealized inventory differentials in the estimation of the excess in the value of inventory at the end of the period over that at the beginning of the period. For, if the excess is positive it acts as a partial offset against other items in the cost of goods sold, thus raising the reported profits; if the excess i negative it must lower the residual figure for profits. Under Fifo, and during inflation, the end period valuation of stock will be greater for identical physical volume of inventories in the opening stock reflecting the advance in prices over the period. Opposite will happen when prices are falling (Note 10). In case of the firms obliged to carry large inventories to operate, and especially if inventory is comprised of commodities subject to wide price fluctuations, Fifo must result, on this score, in magnifying profits (or losses) in an illusory way. To the extent that the results of these accounting processes influence the decisions and actions of individuals and groups, they are important causative factor in trade cycles (Note 11). Further, to the extent that inventory profits are not realized corporate income taxes are assessed on illusory incomes.

\subsection{The Last in First Out (Lifo) Method}

Of the several proposals which have been advanced from time to time for dealing with these problems, accounting has granted recognition only to Lifo which stands for "Last-in first-out." In this method, "inventory is costed as if the units most recently added to inventory (last in) were the first units sold (first out) even though this is in fact not the case. Ending 
inventory is assumed to consist of the oldest units and is measured at those oldest costs (Antony, 1970, p. 231)." The Lifo method is a great accounting innovation. It seeks to squeeze out all water of inventory gains and losses from reported profits, and during periods of rising prices, tends to conserve funds for the firm to maintain a level of inventories commensurate with the scope and intensity of its operations as a going concern. There are, however, some serious objections - both on grounds of theory and feasibility - to its adoption as a universal accounting method. If there is close correlation between the changes in selling prices and those in current costs reflecting a general change in the value of money in the economy, or the rate of inventory turnover is quite fast, Lifo has little advantage over the conventional Fifo system. On the other hand, if there has been a real change in the profit margins in a particular firm which have nothing to do with fluctuations in the price level, the use of Lifo may distort the picture by concealing such changes.

Lifo is obviously not applicable to every firm. It rests on the assumption that there is definite relationship between selling price and current cost of inventories. This, however, need not always be the case. The selling prices of many firms such as those in retail trade are related to the invoice cost of goods and not to their current cost. The use of Lifo in such cases would be illogical and misleading. "Lifo is also not appropriate for companies which eliminate inventory profits or losses by the practice called 'hedging' nor for companies which are in the business of speculating on price changes, as are certain companies that trade in grain and other commodities" Anthony (1970, p. 233).

It is easy to apply Lifo when the inventory consists of fungible products but cumbersome, if not impossible, when inventories consist of numerous unlike items. A so-called Lifo money value method based on the use of price index numbers is in vogue in the United States to obviate this difficulty (Anthony, 1970, pp. 233-236). Appropriate index numbers are not, however, constructed in every country for this purpose, and even if they are, the adjustments would at best be only approximations. Again, there can be several alternatives, in the application of the general idea of Lifo. These variations, most often, only increase confusion.

Furthermore, the cost of materials is just one ingredient of the total cost; reckoning it at current values while other elements like rent, interest, and even wages are charged at their historical values means adding up of non-homogeneous rupees. It is perhaps to remove such inconsistencies that studies sponsored by A.I.C.P.A. and the American Accounting Association have evolved procedures for expressing each item in the profit and loss account and balance sheet in uniform dollars. These procedures are, however, advocated only as a supplement to, and not as a replacement of the conventional procedures (Antony, 1970, pp. 241-242).

\subsubsection{Asset View of Inventory}

If we pass on from the expense-view of inventory to its broader version, the asset-view, a few more dimensions are added to the problem of inventory valuation. Accounting practice in this context regards stock-in-trade essentially as current assets held for realization in future and insists on their valuation at lower of the cost or current price (Note 12). Economists, on the other hand, regard inventories, whatever their stage of conversion, as an integral part of the 
real assets of a going-concern which, like the plant and other facilities, have to be kept intact. The question of the method being appropriate for the purpose apart; we have to decide first the quantum of inventories to be so maintained.

Many times business concerns may carry unusually large inventories from one accounting period to another either as a matter of policy or under the compulsions of market conditions. No one would, therefore, insist that all the opening stock of goods should be maintained. Both the accountants and the economist make a distinction between normal and speculative components of inventory (Marshall, 1946, p. 333, 338). The normal inventory level is what is necessary for a firm to continue its activity without interruption, and to avoid risks of seasonal shortages. The speculative component is referred to by Keynes (1930) as surplus stock which constituted the liquid capital composed of inventories over and above the normal quantities needed for production and distribution. It is suggested that only the normal component of inventories should be maintained in some real sense (Bray, 1952, 76).

The problem, however, is how to ascertain the normal component of inventory. Clearly, this has something to do with the scale of output; an objective and stable criterion can hardly be evolved for such ascertainment. Much will depend in each case on judgment. And as soon as we bring in subjective considerations in our estimates the normal and surplus stocks begin to wear the garment of planned and unplanned inventories - terms which have gained currency in the literature on trade cycles. Economic theory has frequently assumed a constant inventory-sales ratio as criterion for estimating planned and unplanned inventories; such an assumption, however, seems to be quite arbitrary.

Even if it were possible to ascertain objectively the normal inventory requirements for a going concern, the effort to maintain inventories in some real sense can hardly ignore their speculative component if we want to deal effectively, and in a fuller way, with the problem of inventory profit (or loss).

It is interesting to note that while Lifo is a close approximation of replacement costs for the purpose of profit measurement, it may impair the usefulness of inventory figures for the balance sheet. For, under Lifo "inventory is valued forever in terms of whatever the price level happened to be at the time Lifo was introduced. As time goes on and price levels change, the inventory figure under Lifo departs further and further from reality, becoming neither a reflection of actual purchase costs nor of current costs" (Anthony, 1970, p. 233).

It then comes about that from the viewpoints of theory as well as feasibility, considerations of replacement of inventory should be dealt with as questions relevant to the utilization of the profit rather than its measurement. While inventory valuation both for purposes of the profit and loss account and balance sheet may be continued according to the conventional accounting procedures, adjustments pertinent to replacement values may be given effect as appropriation of profit through an Inventory Stabilization Account which would find its place in the balance sheet.

This way of dealing with inventory profits (of losses) has some distinct advantages. It leaves the basic concept of profit ex-post. There is no need to demarcate between planned and 
unplanned inventories. The magnitude of and changes in the balance of this account from time to time may help business management formulate expectations with correct prospective and to that extent may absolve accounting techniques from the charge of accentuating booms and depressions. And last, though not the least, the accountant may provide the economist with useful data on inventory profits without sacrificing much of his traditions and outlook.

\section{Impact of Conservatism}

We have seen that the gap between original values of fixed assets and inventories and their replacement costs can be easily taken note of within the existing framework of modern accounting. Unfortunately it is not so much the historicity of accounting data that vitiates the measurement of profits as its strict adherence to conservatism. The narrow proprietorship point of view is at the root of this conservatism and has been further reinforced by the desire to play safe in the face of uncertainty about the future. Conservatism in accounting practice means "the avoidance of overstatement of assets even at the risk of their gross under-statement, the avoidance of under-statement of debts even at the risk of marked over-statement and the avoidance of over-statement of proprietary and periodic profit. That these objectives are often time inconsistent, and perhaps even contradictory, is widely recognized; nevertheless conservatism prevails as a rule of conduct (Mountz, 1951, 162).

An important influence of conservatism has been the adoption of narrow definition of costs in accounting. Based on some easily verifiable evidence, the term is restricted to include only the cash outlays related to the item in question in a fairly obvious way. Most overheads of indirect costs including interest do not enter into the cost of assets. Indeed, these indirect costs are considered current expenses. Furthermore, certain important expenses such as proprietary capital are ordinarily omitted altogether because of the emphasis on explicit contractual costs. This restricted view of costs distorts the measurement of current profit in three ways (Monitz, 1951, 161-163).

(1) To the extent that investment and fixed assets are under-stated because of the restricted definition of cost used, reported profit will be under-stated during the period when investments are being made and will be exaggerated in subsequent periods when these under-stated assets are converted into receipts from customers. In brief, profits will be shifted in the records from the earlier to the later periods.

(2) Conservatism also requires that certain costs such as are incurred in developing future markets by means of advertising brand names and other promotional devices, or in developing improved operational methods by means of research and development work in general even though explicit be denied status as investment in assets. Instead, they are immediately classed as expenses and hence the recorded profit as well as capital of the concern is understated.

(3) Future receipts are not recorded until they assume the form of enforceable contracts with outsiders. Inventory items are, for instance, valued at acquisition or fabrication cost, narrowly conceived, until sold. At the point of sale all the growth since acquisition is reflected, so that recoded revenues in the period of sale contain the value accretion 
properly assignable to earlier periods. If the rate of inventory turnover is high, this characteristic is not of serious consequence; however, if it is low the distorting effect of conservatism is quite pronounced. What is true of inventories is also true of the fixed assets (Note 13).

These distorting effects on profit measurement not only intensify cyclical phases but as the data from accounting records are the most important source for social accounting; it is advisable that the accountants should discard conservatism in favor of adherence to realities of the situation. They can remain un-concerned only if they refuse to recognize that their profession has any sense of mission or social responsibility.

\section{Conclusion}

The professional duties and approaches of accountants and economists are so different that their views on the definition nature and role of profit are bound to differ. This paper has explored and explained the main reasons of the differences. We have also indicated the possible ways a reduction can be attempted. The micro focus of accounting techniques, preference of historical values and conservatism in the measurement of profit restrict the use of figures for broader macroeconomic and social welfare goals. An important limitation of accounting measurement of profit is lack of incorporating environmental costs into the system.

There are, however, limits to which accountants can be expected to modify and adapt their art to meet the requirements of the social calculus and economic modeling without impairing or making cumbersome the duties which are their primary concern. These limits must be recognized by those enthusiasts who seek reform in accounting techniques and procedures and would like the accountant to take care of their needs (Note 14). The accountant, placed as he is, can hardly become interested in all the social and economic ramifications of trade, commerce, and industry. It is wiser to be content with reforms in accounts not so radical in nature as would vitiate the very object of accounting, and supplement and adjust the data provided by the accountant for social and economic purposes. The suggestions made in the foregoing pages should be viewed in this perspective.

\section{Acknowledgements}

We are grateful to DR. Julian Wells, Principal lecturer economics, Kinston University London, who found my working paper via the NEP-HME listings and was kind enough to send me Chapter 2 of his work and bibliography relevant to the topic as enclosures. I could not make use of his study because his focus and thrust are much different from my objectives and approach. What is common between us two is that he also takes the side of the accountants, his warrant being the work of Geoff Harcourt (1989), who, he says, was among the first to develop a deep analysis of measurement of profit issue. Some of the entries from his list are reproduced below the references as readings for future researchers in the area.

\section{References}

Anonymous. (1946). Value and capital. Oxford: Crandon Press. 
Antony, B. N. (1970). Management Accounting, Text and cases. Richard D. Irwin, Inc.

Bray, F. S. (1952). Measurement of profit. Macmillan, UK.

Break, G. F. (1954). Capital maintenance and the concept of income. University of California Press. https://doi.org/10.1086/257460

Bryer, R. A. (1993). The late nineteenth century revolution in financial reporting: Accounting for the rise of investor or managerial capitalism? Accounting, Organizations and Society, 18(7/8), 649-690. https://doi.org/10.1016/0361-3682(93)90048-B

Bryer, R. A. (2000). The history of accounting and the transition to capitalism in England. part -one - theory. Accounting, Organizations and Society, 25(25), 131-162. https://doi.org/10.1016/S0361-3682(99)00032-X

Crum, W. L. (1932). Corporate size and earning power. Harvard University Press.

Fisher, I. (1969). Income and capital', in Readings in the concept and measurement of income (pp. 33-53). Cambridge: Cambridge University Press.

G. C. (1969). The accountant in a golden age (pp. 127-131). Cambridge: Cambridge University Press.

Griffin, P. A. (1982). Usefulness to investors and and creditors of information provided by financial reporting: A review of empirical accounting research. Financial Accounting Standards Board, Stamford, Connecticut, Harcourt.

Hasan, Z (2016). Theory of profit with Islamic directions (Appendix pp. 162-178). Paragon, UK.

Hicks J. R. (1960). Social framework. Oxford: Crandon Press.

Jeremy, K. J., \& Mayer, C. (1987). The economic analysis of accounting profitability. Oxford: Clarendon Press.

Kaldor, N. (1969). The concept of income in economic theory (pp. 123-124). Cambridge: Cambridge University Press.

Keynes, J. M. (1930). A treatise on money. Cambridge, UK.

Marshall, A. (Eightieth edition 1946 print). Principles of economics. Macmillan, UK

Mountz, M. (1951). The valuation of business capital - An accounting analysis. American Economic Review.

Parker, R. H., \& Harcourt, G. C. (Eds.1969). Readings in the concept and measurement of income. Cambridge: Cambridge University Press.

Pigou, A. C. (1932). Economics of welfare. Macmillan, UK.

Salamon, G. L. (1982). Cash recovery rates and measures of firm profitability. Accounting Review, 57, 292-302. 
Salomon, G. L. (1985). Accounting rates of return. American Economic Review, 75, 495-504.

Vassili, J. de L. (2017)/The Book and the Spirits of Capitalism. Retrieved from https://link.springer.com/chapter/10.1007/978-3-319-32333-6_2 >

\section{Notes}

Note 1. "... the preliminary record of a fixed asset in the books of an enterprise is always made at the amount of money for which it was bought" and even when "assets are revalued ... a balancing adjustment is always necessary to the monetary statement of proprietorship worth" (Bray, 1952, p. 16).

Note 2. "The purpose of income calculation in practical affairs is to give people an indication of the amount which they can consume without impoverishing themselves. Following out this idea it would seem that we should define a man's income as the maximum value which he can consume during a work and can still expect to be as well off at the end of the work as he was at the beginning" (Hicks, 1946, p. 172).

Note 3. "F. Sschimidt made the first formidable attempt as early as 1927 towards erecting the shortcomings of Accounting into a causative factor in business cycles" says Maonitz (1951, p. 157).

Note 4. Revaluation Accounting developed and is now well-established as a tool of business management in recognition of these facts. The general accounting approach however continues along the traditional lines.

Note 5. Pigou A.C. (1932, pp. 45-49; 1935, pp. 235-241 and 1941, pp. 271-275) has been one of the main supporters of this viewpoint.

Note 6. For a lucid discussion of the various income concepts see Break, George F. (1954, pp. 48-62).

Note 7. To find qi we can divide the scrap value of the asset by the price (pi) of an identical new asset at the time tn.

Note 8. "(Real value maintenance) RVM income is in fact is simply IVM (initial value maintenance) money income converted into real income through division by a Paasche type price index" Break (1954, p. 55).

Note 9. It is sometimes suggested that the income (profit) flow is more important rather vital to the existence of a firm than the output flow. Hence the former need be maintained unchanged while the latter may be allowed to fluctuate. This in brief is the Prospective Income Maintenance concept. However, it suffers from many more blemishes than the RCM concept of income.

Note 10. If the change in price over the period is quite sharp or the physical volume of inventories has not changed much over the period, the direction of excess in value may even fail to reveal the direction of physical excess in inventory stock. 
Note 11. "The intensity of cyclical movements is magnified by inventory profits and losses and even the shape and timing of cyclical movements may be distorted in some degree for the same reason", says Crum (1932, p. 275).

Note 12. It is interesting to note that this 'lower of the cost or current price rule' would give double advantage to the firms adopting the LIFO system. The American Income Tax laws do not, therefore, allow companies using LIFO to adjust their inventories at the end of their accounting year according to this ru

Note 13. "The services of the fixed assets in particular may not be converted into receipts for many years. Meanwhile the accountant will reflect these services at cost, again narrowly defined There full growth and fruition will not be recognized until the period of the output into which these resources have been incorporated is over. As a consequence, we find a tendency for revenue to be exaggerated on the on hand by reflections in period of sale of all the growth accruing to the item sold and for revenues to be understated,

Note 14. Accounting data will always be lacking in form and details to meet the needs .of economic modeling. Econometric works that have profit as a variable use data from accounting records unwittingly assuming that figures obtained meet their conceptions of profit. The limitations of the data to serve their purpose need at least be mentioned. This is all the more necessary if the work has an Islamic angle as well.

\section{Copyright Disclaimer}

Copyright for this article is retained by the author(s), with first publication rights granted to the journal.

This is an open-access article distributed under the terms and conditions of the Creative Commons Attribution license (http://creativecommons.org/licenses/by/3.0/). 